Utah State University

DigitalCommons@USU

\title{
Women, Higher Education, and the Labor Market: A Cross-Cultural Understanding of the Impact of Religion
}

Allison Fife Hale

Utah State University

Follow this and additional works at: https://digitalcommons.usu.edu/honors

Part of the Economics Commons

\section{Recommended Citation}

Hale, Allison Fife, "Women, Higher Education, and the Labor Market: A Cross-Cultural Understanding of the Impact of Religion" (2015). Undergraduate Honors Capstone Projects. 566.

https://digitalcommons.usu.edu/honors/566

This Thesis is brought to you for free and open access by the Honors Program at DigitalCommons@USU. It has been accepted for inclusion in Undergraduate Honors Capstone Projects by an authorized administrator of DigitalCommons@USU. For more information, please contact digitalcommons@usu.edu.

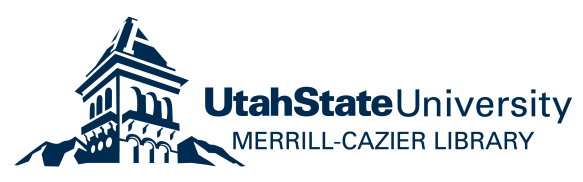




\title{
WOMEN, HIGHER EDUCATION, AND THE LABOR MARKET: A CROSS-CULTURAL UNDERSTANDING OF THE IMPACT OF RELIGION
}

\author{
by \\ Allison Fife Halc \\ Thesis submitted in partial fulfillment \\ of the requirements for the degree \\ of \\ HONORS IN UNIVERSITY STUDIES \\ WITH DEPARTMENTAL HONORS \\ in \\ Economics \\ in the Department of Economics and Finance
}

Approved:

Thesis/Project Adotsor

Director of Honors Program

Dr. Shannon Peterson

Dr. Kristine Miller

UTAH STATE UNIVERSITY

Logan, UT

Summer 2015 


\begin{abstract}
How do deeply-held cultural perspectives shape the desire and ability of women to pursue higher education and or careers? More specifically, how do predominant religious and cultural perspectives on the family, the role of women, and the role of education influence a woman's decision to obtain higher education and her perceived ability or desire to seek full-time employment upon graduation? To answer these questions, this research utilized a cross-cultural survey instrument to compare and contrast the perceptions of female, undergraduate students in one predominantly Muslim/Middle Eastern society -- Dubai, U.A.E -- and one predominantly Mormon/Western society -- Utah, U.S.A. We find that despite diverse cultural backgrounds, Islam and Mormonism have remarkably similar perceived effects on attitudes towards work, family, and education among young, college-aged women in both societies. In particular, we find that women in both cultures place family interests firmly above career and education, although the latter are clearly intertwined with expectations of the dominant religion. Given the growing interest on female perceptions in the workforce and the ability of women to "balance" career and family interests, this research helps fill the gap in cross-cultural knowledge on this topic and, in particular, helps us gain further insight on the influence of religion in determining attitudes towards work, family, and higher education.
\end{abstract}




\section{Acknowledgements}

The author is grateful for the support of the USU Honors Program, Undergraduate

Research Fellows Program, Huntsman Scholars Program, Jon M. Huntsman School of Business, and College of Humanities and Social Sciences. She would also like to specifically thank Dr.

Shannon Peterson and Professor François Dengah for guidance in Utah, Dr. Stacey Hills of Southern Vermont College for her help with data analysis, and Professor Candy McLeod, Ms. Haya Al Mutlaq, and the Insight Dubai Conference for support in the UAE. 


\section{Table of Contents}

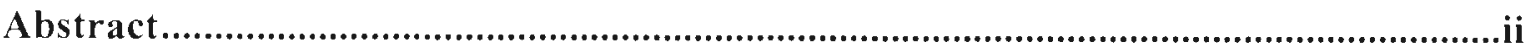

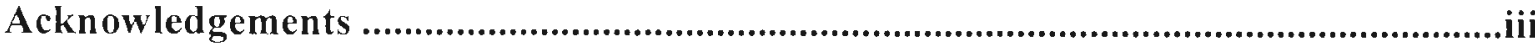

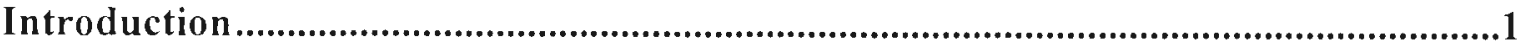

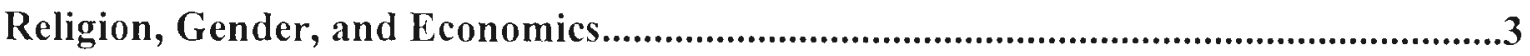

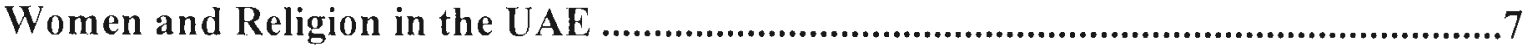

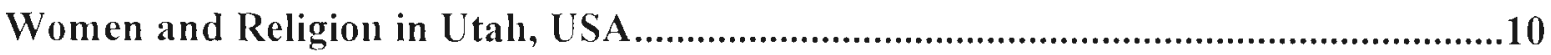

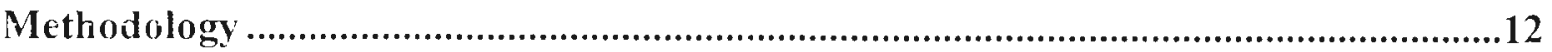

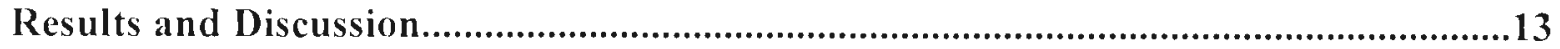

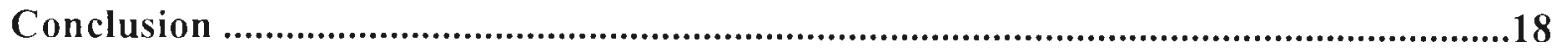

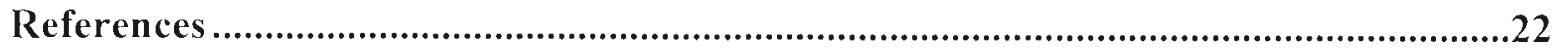

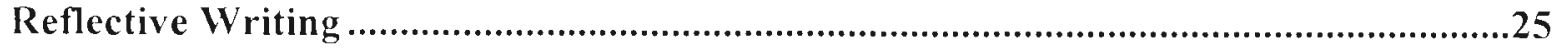

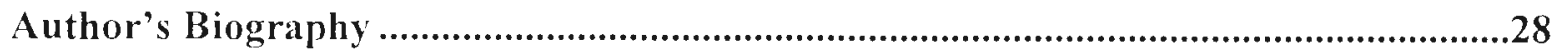

\section{List of Tables}

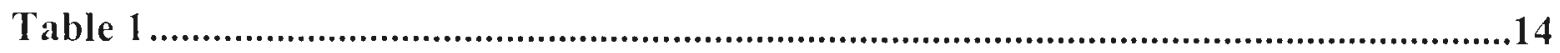

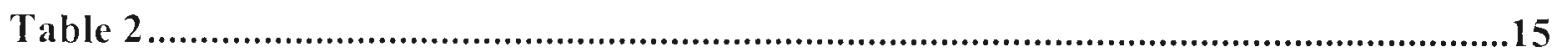

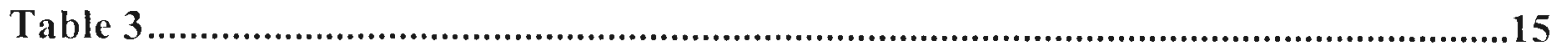

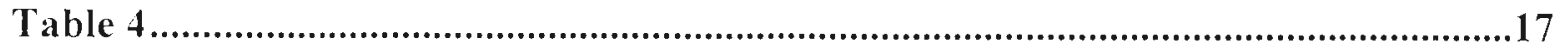

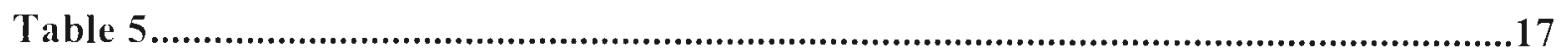




\section{Introduction}

Religion is often considered part of cultural practices that dictate and shape women s rights and perceived roles in various regions of the world. The relationship between religion and culture, the influence of culture on economics, and the very definition of "culture" or "cultural perspectives" has been broadly discussed over several academic disciplines. Scholar Mark Hulsether (2005) identifies the complex challenges inherent in studying "culture" in general and "religious culture" in particular in a thorough and foundational analysis for The Routledge Companion to the Study of Religions. Despite the potential dangers of "culture as a boundless field in which to flounder" and the understanding that "the level of abstraction required for cross-disciplinary conversation can be off-putting," Hulsether affirms that "the skill of using cultural theory like a rail network to connect scholarly places-to move between different homes for constructive purposes---is extremely useful" (pg. 501). From his analysis, the method of interdisciplinary cultural studies represents "more than a body' of work," rather "it is a way of framing questions" (pg. 499).

The questions this research attempts to address are complex and multi-faceted. Is there a "best way" to understand how religious influences may shape economic decision-making? As theology often differs from the lived experience of religion, we have decided to take a cultural approach-with the assumption of religion as a subset of culture.' Using cultural theory as a framework and a survey revealing individual perceptions of cultural influence on goals and interests, we hope to open further

\footnotetext{
I "Is culture a subset of religion or vice versa? We cannot ride both these definitional horses at the same time." Hulsether provides further evaluation of these two "definitional horses" for those wary of assuming religion as a subset of culture, illustrating the advantages and disadvantages of each approach. We focus on religion as a subset of culture based on his conclusion that "we have seen that religious subsets of culture may overlap extensively with the umbrella category [of culture], sometimes to a point where for practical purposes they coincide. Because of these overlaps. there is a major benefit in approaching religious studies as the study of religious cultures. It allows us to translate analyses of religions--their genealogies, relations with power, prospects with in postmodern society, and so on-into analyses of culture.... Since many subjects besides religion can be approached in the same way, cultural theory has become a lingua franca for work from many disciplines. A common language of culture can translate between incommensurate vocabularies used in different disciplines, thus bringing diverse research to bear on particular problems." (pg. 500-501)
} 
conversation about the connections between religious cultures and women's economically-related decision-making with regards to education and employment. Here, we are guided by an understanding of culture within the framework of cognitive anthropology, defined as "the study of human thought in the context of social relations" (Dressler et al. 2004, 140-141) or as "the study of human cognition in cultural and cross-cultural contexts" (Bennardo 2013). Specifically, we reference a cognitive understanding of culture "as the knowledge an individual must possess to function adequately as a member of a social group" (Goodenough 1957 in Dressler et al. 2004). Within this frame, we draw an implied connection between gender-based expectations within religious culture (knowleage) and the perception of available work or educational opportunities (function). Specifically, this research seeks to answer the following questions. How do deeply-held cultural perspectives shape the desire and ability of women to pursue higher education and/or careers? More specifically, how do predominant religious and cultural perspectives on the family, the role of women, and the role of education influence a woman's decision to obtain higher education and her perceived ability or desire to seek full-time employment upon graduation? Moreover, given the cross-cultural nature of our study, are these religious influences similar despite distinct differences in nationalities and other cultural characteristics?

In addition to an anthropology-based definition of culture, as an interdisciplinary study, we draw heavily upon relevant literature from economics, sociology, and history to contextualize our findings. We do so in an attempt to convey the complexity of these issues, while still providing clarity and critical evaluation of our research questions. As context, we will first review the relevant literature that studies interactions between economics, religion and gender. Then, we will provide a summary of key literature that contextualizes observed gender roles, rights, and economic expectations or opportunities within each culture in this study (Muslim culture in Dubai, UAE, and Mormon culture in Logan, UT). Finally, we provide our findings and draw conclusions. 


\section{Religion, Gender, and Economics}

In many respects, decisions to further education or pursue a career and/or family are economic choices. On an individual level, these decisions can impact a woman`s earning potential and career options; collectively, they can impact the productivity, innovation and economic growth of a nation. To better understand how religion can influence this economic behavior, we explored the academic literature on the subject.

Academicians and policy makers have long been interested in the potential interplay between religion and economics. In his foundational "Introduction to the Economics of Religion," Iannccone (1998) classifies this literature in three general categories: studies that interpret religious behavior through an economics lens, studies of the economic consequences of religion, and "religious economics," which he defines as the work of those who use religious texts to justify or criticize economic policies. Most of the literature, by far, has been that focused on the "economic consequences of religion." Famously, Weber (1930) pioneered the argument that religion directly impacts the economic success of nations. Specifically, Weber argued that Protestantism was directly conducive to the development of capitalism. Others have made similar arguments, such as Landes' assertion that Catholicism was responsible for the institutions that left the economies of southern Europe lagging in the early modern period relative to the Protestantism of more productive northern European countries (Landes 1998).

These studies, however, may be limited in their ability to directly explain the relationship between religious attitudes and economic change. Guiso et al. (2003) point out the difficulty in distinguishing the "effect of a religion separately from the effect of other historical accidents" (pg. 227) in the previous cross-cultural scholarship. Utilizing the World Values Survey (which covers representative samples from sixty-six countries), these authors sought to isolate the relationship between 
intensity of religious conviction and collective economic attitudes by controlling for country-specific effects. They found that generally, religiosity is linked to higher per capita income and growth. In relation to gender, they acknowledged that "all religions are associated with a more conservative attitude toward women." With respect to specific religions, they noted, "that effect is twice as strong for Muslims than for any other religion" (pg 264). Other studies have continued to suggest a correlation between countries with a dominant Protestant religious culture and economic growth. For example, Feldmann (2007) similarly sought to isolate religion from other factors by controlling for a variety of market influences in his analysis of data from over eighty countries. He suggests that labor force participation, particularly for women, is higher in countries where Protestantism is the dominant religious culture. Moreover, he argues that "countries dominated by other religions (e.g. Catholicism, Islam, Buddhism) are likely to have developed a national culture that does not put a high value on hard and diligent work and may be hostile toward paid employment of women" (pg. 809).

These examples highlight how much of the literature discussing economics and religion has primarily focused on the collective economic outcomes for entire countries or regions based on religious culture. Significantly less work has been done to understand how religious cultures may be related to the specific decision-making attitudes of individuals, and women in particular, when it comes to family, education, or career plans-all decisions that ultimately impact the collective economy of a larger group. A few key studies, taken together, can shed some light on how factors such as religion and gender shape these kinds of decisions. Yet clearly, much more scholarship is needed to more fully understand the intersectionality of gender and economic decision-making in religious cultures.

In the area of education, Keysar and Kosmin (1995) sought to "test the hypothesis that religion is significantly associated with the acquisition of postsecondary education of women" (pg. 50). Ultimately, they argue that because different religious traditions place varying importance on family, marriage, and 
child-bearing, "religion has an indirect effect on the educational levels of women through their demographic behavior," and that "the relationship between religion and the education of women is maintained even beyond other social and demographic factors" (pg. 50). Others have taken a different approach. Kaufman (2005), for instance, tries to understand the work and family expectations of American college students with relation to their articulated gender role attitudes without explicit reference to religiosity. Both her results and her assessment of previous gender scholarship suggest that "most college students will expect to work full-time and have a family. However, female college students are likely to realize the persistent expectations that they take on more responsibility for family" (pg. 62).

A number of studies have increasingly tied these kinds of questions together with a focus on the labor market. After an analysis of the literature, Chadwick and Garrett (1998) conclude that, at least within the United States, "only modest support has emerged linking women's religious values to their employment experience" (n.p.) They point out, however, that previous studies may be limited by the measures of religiosity-."different dimensions of religiosity may have different relationships to employment" (n.p.). Few studies have been conducted outside of the United States. Recognizing this limitation of the existing literature (specifically the lack of any known studies using micro-level data to examine the effects of women's labor market activities in developing countries), Amin and Imam (2008) attempt to understand "whether religion is a significant determinant of married and single women's paid-work and full-time employment in Malaysia" (pg. 2369). They find that religion is less influential in urban areas than in rural areas and that religion has a significant impact on the decision of single women to work for pay in both rural and urban areas. Meanwhile, O'Neil and Bilgin (2013) conclude in their research on Turkey that religion's cultural dimensions indirectly influence the career expectations of women via cultural norms and expectations. In particular, women in Turkish society often feel 
constrained from entering into the labor market given religious and cultural expectations that they should fulfill more traditionally gendered roles. According to the authors, religion influences "Turkish women's work decisions to the extent that it supports "patriarchal mentalities" which define women first and foremost as mothers and caregivers" (pg. 163). Here, religious culture may constrain opportunity by narrowly framing the choices available to women with regard to family, work, and education.

With regards to gender more broadly, Geert Hofstede explored its national manifestation in his controversial "masculinity-femininity" cultural dimension. According to Hofstede et al. (2010), a society is regarded as masculine "when emotional gender roles are clearly distinct.." In other words, a "masculine society" would consider men as assertive, tough, and focused on material success, and women as caring, nurturing, and focused on quality of life. In masculine societies, boys are expected to work and aspire for career advancement whereas women will see it as optional, with some wanting a career while most will not. In terms of religious culture, Hofstede et al. (2010) suggest that Christianity and Islam have both masculine and feminine elements. Within Islam, Sunni is said to be a more masculine version of the faith than Shia; within Christianity, Mormonism is said to have strong masculine values whereas Protestantism tends to be more feminine. While this dimension does not appear related to national economic wealth, it is highly correlated with a country's relative religiosity: feminine societies are more secular (Hofstede 2010, pg. 135-185). Relatedly, in terms of individual attitudes, Stotzel (1983) found that when the role of a woman changed from housewife to wage earner, her relative religiosity diminished. From these perspectives, both of the societies selected in this study are more likely to be considered "masculine" as the majority of Utahns are Mormon (i.e. Latter-day Saints) while the majority in the UAE is Sunni Muslim.

In short, the literature suggests that cultural values-particularly religious cultural values--may influence some aspects of economic decision-making. These values can shape gender role attitudes and 
perspectives on particular decisions, such as the role of family, education, or a career. Although there is a growing interest in women's decisions regarding work-life balance and a few studies have examined the relationship between cultural religiosity and labor force outcomes, this complicated relationship has simply not been studied in-depth at a cultural or cross-cultural level. To help fill this gap in the literature, our research explores the perceptions and attitudes of single, college-aged women in two vastly different parts of the world: Dubai, in the United Arab Emirates; and Utah, in the United States of America. While both societies differ considerably economically, politically, and in national culture, they both are also heavily influenced by a single, dominant conservative religion: Islam, in the case of Dubai, UAE, and Mormonism or, as it is officially known, The Church of Jesus Christ of Latter-day Saints, in the case of Utah, U.S.A. The comparison of these two groups allows us to observe whether religion-in particular, traditional, religious-based attitudes towards women and their role in society-constrains individual perceptions of preferred economic roles and opportunities available to women and men.

\section{Women and Religion in Dubai, UAE}

One hundred percent of Emirati citizens are Muslim, and although eighty-five percent of the population of the UAE consists of noncitizens, the overall majority of the population is still Muslim (76\%) (CIA). Among citizens, about $85 \%$ of Emiratis are Sunni Muslim, with the remaining $15 \%$ as Shia Muslims (U.S. Department of State).

Much has been written on the question of women's roles in Islam and women's rights in predominantly Islamic countries, although the relation to economic and educational choices is somewhat limited. Given the diversity in the Islamic world, broad generalizations regarding women's perceptions of work and education in relation to gender may be problematic. Ahmed (1992) reminds, "The investigation of the discourses on women and gender in Islamic Middle Eastern societies entails 
studying the societies in which they are rooted, and in particular the way in which gender is articulated socially, institutionally, and verbally in these societies" (pg. 2).

Acknowledging this complexity and limitations in the literature, understanding the current status, expectations, and perceptions of Emirati women in the predominantly Muslim society of the UAE requires an examination of the existing cultural and legal framework of rights within the boundaries of the region. The current Constitution of the United Arab Emirates, first temporarily adopted in 1971 and permanently set in place in 1996, enumerates various rights and responsibilities of government. In addition to establishing Islam as the official religion of the state, the constitution establishes protections for the family and a variety of social and economic rights. Article 15 asserts that "the family is the basis of society" and that "it is founded on morality, religion, ethics and patriotism." Article 16 continues with the admonition that "society shall be responsible for protecting childhood and motherhood," and Article 17 declares that "education shall be a fundamental factor for the progress of society," guaranteeing equal access to education irrespective of gender. Work is similarly valued; Article 20 suggests that "society shall esteem work as a cornerstone of its development," and outlines the goal to ensure employment and suitable occupational training for all citizens.

The government of the UAE has highlighted the progress and education of women (Ministry 2008). Among these achievements include a high literacy rate among women in the UAE (90\% in 2007), and a higher percentage of women than men enrolled in higher education. These achievements have been fairly recent, however. According to the World Bank (2015), the average labor force participation rate of women in the UAE has risen from twenty-nine to forty-seven percent over twenty years (19932013); in 2011, however, the government of Dubai reported that only $31.37 \%$ of Emirati women (15 years and older, living in Dubai) were economically active; of the $68.63 \%$ of women who were not 
employed, $30.1 \%$ were full-time students and $42.7 \%$ were described simply as a "housewife" (Dubai Statistics Center 2011).

The academic literature surrounding women's roles and rights in the UAE presents a fairly nuanced context for these achievements. For example, al-Oraimi (2004) argues that the discovery of oil and economic transition across the Arabian Peninsula has led to the elimination of traditional roles for women in the political and economic sphere. She determines that the modernization process in the UAE has created new roles for women in society, but feels that women are still "underrepresented and their contributions are devalued" (pg. 2). Al-Oraimi ultimately concludes that "due to the external intervention of modernity, women in the UAE have been undermined and segregated from the public life in many ways and instances" (pg. 2).

In contrast, Pinto (2012) argues that the above-listed protections and assertions by the government of the UAE reflect the state's gender policy as a component of the nation-building process. In trying to understand both how Emirati women have contributed to the development of the Emirates as well as to why the state has "so visibly committed itself to the cause of the expansion of women's rights" (pg. xii), Pinto suggests that the promotion of women's rights is an integral part of the modernization process in the UAE. Realizing that culturally-based, traditional gender roles are deeply ingrained in Arab society, Pinto provides some analysis of recent Emirati history and the role of Islam in reference to local customs before concluding that progress towards greater educational and economic freedom for women has only been possible in the UAE as the state has purposefully assumed the role of a strategic actor in regards to gender rights.

In short, the institutional and perceived role of women in the UAE appears to be in transition. There is a complex relationship between modernization, ingrained tribal cultural traditions, and the official integration of Islam as state religion, and there is an unclear understanding of the impact of this 
transition on women. Moreover, there is an evident lack of relevant sociological and economic studies. As such, attempts to understand the economic perceptions and goals of Emirati women in the context of Emirati culture are significant.

\section{Women and Religion in Utah, USA}

In contrast to the UAE, 62.64 percent of the Utah population officially identifies with the Church of Jesus Christ of Latter-day Saints (Canham-2014). University of Utah demographer, Pam Perlich, explains that "Mormon culture" may be even more encompassing. "People may or may not be actively going to church, but still they would be very connected to the Mormon culture region through their neighborhoods or through their families... It's not just a religious affiliation in Utah. It's also a definition of cultural roots" (Rosenlof 2014).

Although not legally defined and imposed (unlike the UAE, Utah, like other states, recognizes a separation of church and state as protected in the United States Constitution), Mormon cultural values related to family and gender have been prominently articulated in language similar to the protections of the UAE constitution. For example, the official LDS statement "The Family: A Proclamation to the World" (First Presidency and Council 1995) describes "the family as the fundamental unit of society," and suggests that "successful marriages and families are established and maintained on principles of faith, prayer, repentance, forgiveness, respect, love, compassion, work, and wholesome recreational activities." Further, fathers are "responsible to provide the necessities of life and protection for their families," whereas "mothers are primarily responsible for the nurture of their children" (I).

Significantly different kinds of literature exist to contextualize our study of women in Utah from those in the UAE. Detailed studies have tracked various education and employment outcomes for women in Utah for decades, providing a wealth of information to understand the status of women in the labor market of the region. This data often differentiates Utah from other states or regions in the United 
States, calling attention to interesting trends in employment and education that are specific to the state. In a Utah Department of Workforce Services report, Lecia Parks Langston (2010) powerfully describes the economic attitude of many Utah women:

Despite the evidence that most women work in today's economy, many still fail to plan for a career. And, in the end it hurts us-and our children--economically. I once heard it put this way: "Many women have "until' jobs." What does that mean? They plan on working "until" they get married and have children. Then, they plan on working "until" they put their husband through school. Then, they plan on working "until" they pay for a new car. Then, they plan on working "until" they save enough for a down payment for a new house. ... Pretty soon, these women have 30 years of "until" jobs that didn"t pay very well, had few benefits, lacked retirement plans, or provided little satisfaction. ... Because most women see motherhood as their prime career, they fail to plan adequately for a career in the workforce. (n.p.)

Quantitatively, Hess et al. (2015) reported that Utah has the largest difference (in the USA) between men's and women's labor force participation rates (pg. 54), has the largest percentage of the female workforce to work part-time (40.2\%) and (correspondingly) is the lowest ranking state for percentage of women working full-time (pg 74). Utah women who are married with children are least likely to be breadwinners (compared with women from other areas of the United States), with a 42.7 percentage point gap between the labor force participation rate of mothers and fathers (pg. 95, 105). Similarly, the gender gap between men and women who complete higher education is largest in Utah (pg. 133), and although the number of women enrolled in higher education in Utah is growing, it is not keeping pace with the national growth rate for women in higher education ((Utah Department of Workforce Services, 2014). Ranked highly among the states for the amount of women whose highest level of educational 
attainment is "some college or an associate"s degree," (Hess et al. 2015, pg. 158), Utah women "start college studies at above average rates," but are "less likely to complete their degrees" (Perlich 2006, 5).

Whereas research evaluating the relationship between religion and education or labor force outcomes is limited in the UAE, there exists a growing body of work attempting to understand these questions and this data with respect to conservative American religious practice generally and that of The Church of Jesus Christ of Latter-day Saints (Mormon or LDS) in Utah more specifically. For example, Chadwick and Garrett (1998) completed a thorough study of "the relationship between women's religiosity and employment" by evaluating survey responses of " 1,130 women who belong to The Church of Jesus Christ of Latter-day Saints, which has strong pro-family values integrated into its theology." Consistent with Stoetzel (1983), they found that religiosity did have a significant relationship with LDS women's employment, concluding “the stronger a woman's beliefs, the less time she had spent in the workplace." Particularly "for housewives and women who work part-time, religiosity... influences their employment intentions." While this study is significant in understanding the relationship between individual religiosity and labor force participation, however, it does not provide full insight into how women perceive the relationship between a religious culture and their economic decisions or opportunities.

\section{Methodology}

To address our research questions, a survey instrument was designed and given to participants in two locations: the campus of HCT-Dubai Women's College (Dubai, UAE) and Utah State University (Logan, UT, USA). These distribution sites were chosen because of their accessibility (like-minded women were already gathered in classroom settings that could easily be surveyed) and their setting (publicly-funded institutions within cultures demonstrably influenced by a predominant religion). 
Items were developed after examination of the extant literature and conversations with faculty members familiar with the constructs. The instrument was pretested in multiple stages. In the United States, items were tested with undergraduates from a business honors program. These students possess traits that match the target sample population, and items and instructions were edited for clarity and ease of completion. The resulting instrument was shared with students and faculty from the UAE for further clarification and edits, with special attention to cross-cultural language issues. The final instrument was developed as a result of this qualitative feedback. Data were collected via an anonymous Qualtrics Online Survey. A total of 433 responses were received. Upon review, many surveys were left entirely blank, suggesting a reluctance upon at least some subjects to participate in the research. These responses were removed from the data set, resulting in a total of 363 surveys for which at least partial data were received.

The data were then further refined to compare two women-only cohorts. The first cohort $(n=73)$ included American women living in Utah, USA, while the second $(n=56)$ represents women from the United Arab Emirates living in Dubai. To maximize the generalizability of results, partially completed surveys were retained and utilized wherever possible in the data analysis. Mean substitution was utilized in a few instances to allow the entire cohort to be used for analysis. The data were analyzed using Microsoft Excel, including tests for mean difference and tests for difference in proportion.

\section{Results and Discussion}

Analysis began with an examination of cultural values and religiosity through cohort responses. From this, the most striking finding is the overall similarity between the two groups. Both the Utah and UAE samples perceived the cultural values of their society as moderately religious but also highly influenced by the dominant religion ( $89 \%$ Utah; 90\% UAE), although the Emirati sample perceived a significantly closer link between the dominant religion and prevailing cultural values $(\mathrm{p}<.001 ; 3.822$ 
Utah v. 4.357 UAE). Interestingly, both groups similarly linked their perception of educational and career opportunities to predominant cultural values: majorities agreed that there is a relationship between educational opportunities (72.6\% Utah, 69.6\% UAE) and their home society's cultural values, and between career opportunities (71.2\% Utah, 71.4\% Dubai) and common cultural values.

In fact, both groups perceived their home societies as generally emphasizing the importance of families over careers and education (Table 1). A significant difference is that Utah women perceived the pursuit of careers as generally more important in their home culture than did the Emirati women $(22.2 \%$ and $1.9 \%$ respectively; $p<.01$ ). When asked specifically about their perceptions of respective cultural attitudes towards women, however, we also note some interesting differences, as illustrated in Table 2. While both saw their cultures as encouraging education for women (90.4\% Utah; $89.3 \%$ UAE) and giving priority to family ( $86.3 \%$ Utah; $78.6 \% \mathrm{UAE})$, the Emirati sample was significantly more likely to say that their culture encouraged women to pursue a career than the Utah sample $(58.9 \%$ Utah; $82.1 \%$ UAE, $\mathrm{p}<.01$ ), a result that contrasted with perceptions of general cultural values.

Table 1: Perceived Values of Home Society, in Order of Importance

\begin{tabular}{|l|l|l|l|}
\hline$\%$ Ranking as $\mathbf{1}^{\text {st }}$ Priority & Education & Family & Career \\
\hline UAE $(\mathbf{n}=\mathbf{5 2})$ & $15.4 \%$ & $82.7 \%$ & $1.9 \%$ \\
\hline Utah $(\mathbf{n}=\mathbf{7 2})$ & $12.5 \%$ & $65.3 \%$ & $22.2 \%$ \\
\hline $\mathbf{z - s c o r e}$ & -0.479 & -2.186 & 3.305 \\
\hline Significance & n.s. & $<.01$ & $<.01$ \\
\hline
\end{tabular}


Table 2: Perceptions of Home Society's Attitudes Towards Women

\begin{tabular}{|c|c|c|c|c|}
\hline $\begin{array}{c}\text { Women are } \\
\text { generally } \\
\text { encouraged to... }\end{array}$ & UAE $(n=54)$ & Utah $(n=73)$ & z-score & Significance \\
\hline $\begin{array}{l}\text {..obtain an } \\
\text { education. }\end{array}$ & $89.29 \%$ & $90.41 \%$ & 0.21 & n.s. \\
\hline $\begin{array}{c}\ldots \text { pursue a } \\
\text { career. }\end{array}$ & $82.14 \%$ & $58.90 \%$ & -2.828 & $<.01$ \\
\hline $\begin{array}{l}\text {...give priority } \\
\text { to family. }\end{array}$ & $78.57 \%$ & $86.30 \%$ & 1.157 & n.s. \\
\hline $\begin{array}{l}\text {...pursue their } \\
\text { own unique } \\
\text { path to personal } \\
\text { fulfillment. }\end{array}$ & $51.79 \%$ & $53.42 \%$ & 0.185 & n.s. \\
\hline
\end{tabular}

These differences in perceptions are intriguing when compared to the women's personal goals and priorities. As seen in Table 3, when asked to rank their personal goals given the same three options, both groups rank ordered family as their highest priority (75.3\% Utah; 90.9\% UAE), followed by education $(13.7 \% ; 7.3 \%)$, and a career $(9.9 \% ; 1.8 \%)$, with the Emirati sample being significantly more likely to rank family first and career last than the Utah sample $(p<.01$ and $p<.10)$. In summary, while Utah women were more likely to perceive their home culture as valuing career over education (Table 1), Table 3 illustrates that this perception of cultural priorities did not necessarily translate into personal ones. This can perhaps be linked by the results in Table 2, which suggests that Utah women do not believe they specifically are encouraged to pursue a career.

Table 3: Ranking of Personal Goals

\begin{tabular}{|l|l|l|l|}
\hline \% Ranking as $\mathbf{1}^{\text {st }}$ Priority & Education & Family & Career \\
\hline UAE $(\mathbf{n}=\mathbf{5 5})$ & $7.3 \%$ & $90.9 \%$ & $1.8 \%$ \\
\hline Utah $(\mathbf{n}=\mathbf{7 3})$ & $13.7 \%$ & $75.3 \%$ & $9.9 \%$ \\
\hline $\mathbf{z}$-score & 1.148 & -2.274 & 1.851 \\
\hline Significance & n.s. & $<.01$ & $<.10$ \\
\hline
\end{tabular}


As illustrated above, the analysis also indicates that some statistical differences between the Utah and Emirati beliefs were merely a matter of degree rather than actual difference in overall perspective. When asked if equal educational opportunities currently exist, $70 \%$ of the Emirati sample said "definitely yes" compared to only $48 \%$ of the Utah sample. This difference was statistically significant, illustrating that Emirati women perceived relatively greater equality of educational opportunity than did the Utah women $(\mathrm{p}<.01 ; 1.876$ Utah v. 1.482 UAE). Relatedly, when asked if there should be equal educational opportunities, there were again statistically significant differences between the groups $(\mathrm{p}<.05 ; 1.00$ Utah $\vee .1 .089 \mathrm{UAE})$, with the Utah sample perceiving a greater need for equality in educational opportunities between women and men.

In terms of career opportunities, respondents were asked, "in your home society, do you feel like there are equal career opportunities for women and men?" Both samples failed to perceive high equality between the sexes. Similarly to the results for education, with respect to career opportunities, Emirati women were more likely to perceive greater actual equality of career opportunities between the sexes in their home society $(\mathrm{p}<.01 ; 2.411$ Utah v. $1.911 \mathrm{UAE})$, whereas Utahn women were more likely to perceive that there should be greater equality of opportunity $(p<.05 ; 1.027$ Utah v. 1.143 UAE).

Differences in the strength of perceptions also existed when respondents were asked to identify the primary purpose of an education by force ranking four choices: the pursuit of knowledge (to develop one's own personal knowledge and growth); to gain a career (to prepare for future career/occupation); to pursue a family (to become a better spouse and to raise a family); and to become a good citizen (to become a better and more informed member of society). Table 4 represents the percentage of respondents naming each item as a primary or secondary purpose. 
Table 4: Perceived Purposes of an Education

\begin{tabular}{|l|l|l|l|l|}
\hline \% Ranking as $\mathbf{1}^{\text {st }}$ or $\mathbf{2}^{\text {nd }}$ Purpose: & Knowledge & Career & Family & Citizenship \\
\hline UAE $(\mathbf{n = 4 8})$ & $66.7 \%$ & $52.1 \%$ & $45.8 \%$ & 35.4 \\
\hline Utah $(\mathbf{n}=\mathbf{7 0})$ & $87.1 \%$ & $68.6 \%$ & $20.0 \%$ & $24.3 \%$ \\
\hline z-score & 2.67 & 1.81 & $(-2.99)$ & $(-1.31)$ \\
\hline
\end{tabular}

As seen in Table 4, majorities in both groups perceived that the primary purpose of education is to facilitate personal growth and career development, followed by family preparation and civic training. When z-tests for the differences in proportions were performed, no statistical differences existed in the prioritization of citizenship, and only slight differences were found with respect to career $(p<.10)$. Interestingly, strongly significant results were identified for both the perceived purposes of knowledge and relevance to family $(\mathrm{p}<.01)$. While personal knowledge and career were seen as greater educational priorities for the Utah sample, respondents from the UAE were more likely to identify pursuing a family as an educational purpose.

When asked about future plans for education, career and family, differences also existed. Table 5 shows the percentage of respondents planning to: complete an undergraduate education, complete a graduate degree, have a full-time job, have a part-time job, and/or start a family.

Table 5: Personal Plans for the Future

\begin{tabular}{|l|l|l|l|l|l|}
\hline \% Plan for: & Ugrad Degree & Grad Degree & FT Career & PT Career & Family \\
\hline UAE (n=56) & $60.71 \%$ & $73.21 \%$ & $53.57 \%$ & $19.64 \%$ & $58.93 \%$ \\
\hline Utah (n=73) & $93.15 \%$ & $50.68 \%$ & $82.19 \%$ & $30.14 \%$ & $86.30 \%$ \\
\hline z-score & 4.49 & $(-2.59)$ & 3.51 & 1.35 & 3.53 \\
\hline
\end{tabular}


A z-test for the differences in proportion was conducted for each item, and statistically significant differences $(\mathrm{p}<.01)$ were found for all but starting a part-time career (n.s.). Interestingly, a greater percentage of US students planned for all items except attaining a graduate degree.

\section{Conclusion}

In our efforts to understand the relationship between perceptions of dominantly-influenced religious culture and relevant economic outcomes, these results provide both striking similarities and interesting differences. The strongest conclusion from our research is simply the remarkable similarity in attitudes and perceptions between both groups. Despite differences in nationality, ethnicity, and religion, traditional female gender roles were affirmed in both cultures. Both home cultures were perceived as being dominantly influenced by a single religion, and the associated religious cultural values were perceived as influencing educational and career expectations and opportunities for women. All in all, these overwhelming similarities suggest that women do observe a relationship between the religiosity of their societies, available educational and career opportunities, and societal expectations for women.

Returning to a cognitive definition of culture, this knowledge may partially shape the personal goals and priorities of individual women as they balance perceived expectations and opportunities with action. This link (between societal perception and personal priority) was not always entirely clear. For instance, Utah women desired to pursue a family and education over a career, which is only partially consistent with their perceptions of societal values; Tables 1 and 2 suggest that Utah women perceive their society as prioritizing career over an education generally, but highlight that women specifically are encouraged to make their career or a unique path of personal fulfillment their last priority. These nuanced observations may provide further insight into the institutionalization of gender role expectations within Utah society, but also reflect a complexity of cultural perception that could be studied further. Yet overall, these results still affirm much of the previous literature relevant to each respective location. 
In the UAE, for example, the strong perception that women are encouraged to pursue an education fits well with the state's active gender policy and constitutional affirmation of educational rights. In Utah, the tendency to rank career last among personal goals and to strongly perceive society as encouraging women to prioritize family over a career is consistent with dominant Mormon cultural values and relates to documented workforce trends (such as the high number of part-time workers, high labor force participation gap between mothers and fathers, and an expectation of the "until" job).

Despite similarities, some interesting differences in the strength of attitudes and perceptions exist to shed further light on women's perception of gender equality at the national level. For example, Emirati women perceive their society as providing more equal career and educational opportunities for men and women and therefore perceive less need for change, which suggests a greater satisfaction with the current perceived state of national affairs. In contrast, Utah women perceived less actual equality but more strongly affirmed that educational and career opportunities should be equal, potentially signaling national cultural differences between the two samples. In addition, Emirati women were more likely to indicate their desired pursuit of a graduate education than were Utah women. This difference could be reflective of a number of factors, both economic and cultural. First, is the relative cost of higher education in the two countries. Whereas higher education is available for free to Emirati women in the UAE, it is not available for free to most American women in the USA. ${ }^{2}$ These costs combined with emphasis on family in LDS doctrine (and subsequently Mormon culture) may result in relatively lower graduation rates for Utah women when compared to the national average. National culture may also help

\footnotetext{
${ }^{2}$ According to the UAE Embassy in the US, higher education is free to all citizens, which leads it to have "one of the highest application participation rates in the world. Ninety-five percent of all girls and 80 percent of boys enrolled in the final year of secondary school apply for admission to a higher education institution. (http:- www.haecd orghigher-education, accessed June 4, 2015). In contrast, according to their comparative study of higher education in 15 countries, Usher and Medow (2010) ranked the United States 13 in terms of affordability, with the average educational costs of $\$ 13,856$ and a median income of \$26,990. See Alex Usher and Jon Medow (2010), Global Higher Education Rankings 2010: Affordability and Accessibility in Comparative Perspective. Higher Education Strategy Associates. http: Wm! ires-

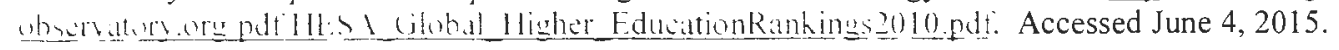


explain the differences in perceived purposes of education between the two samples: whereas Utah women were more likely to connect the purpose of an education to individual growth, Emirati women were more likely to connect it to family. These differences could be reflective of the more individualistic American culture as opposed to the more collectivist Emirati culture. ${ }^{3}$

In conclusion, as our data and research is admittedly limited in size and scope, the need for more research is apparent. This research was primarily limited by our samples. In particular, our samples were partially biased as all of the women surveyed were already university students actively participating in higher education. As such, one would expect them to be more likely to favor educational achievement. Similarly, students in both samples were primarily drawn from business classes, which may lead them to be more "career-inclined" than those studying in other fields. Finally, both samples were drawn from relatively affluent societies, which one would also assume may influence economic choices, such as a pursuit of career or higher education. As a result of these sample biases, a more comprehensive survey would include women from more diverse educational and economic backgrounds. Additional studies should also be conducted in societies with different national, ethnic, and religious backgrounds from those highlighted here. Despite these limitations, these findings may help catalyze a deeper examination of the intersectionality of gender, religious culture, and economic decision-making.

In particular, we see this preliminary study underscoring the important cultural role of religion in socializing gender roles and in framing the educational and career choices that can ultimately shape individual and collective economic outcomes as well as personal satisfaction. As societies develop economically and global economic and informational forces encourage more women to enter into higher education and the work force, the questions of change and adaption arise. For example, will relatively conservative religious societies adapt and conform to more secular economic forces, or will they be able

\footnotetext{
${ }^{3}$ According to the Hofstede website, the United States is much more individualistic in its orientation than is the UAE, with a ranking of 91 out of 100 ( 100 as perfectly individualist) compared to 25 out of 100 for the UAE.
} 
to maintain their strong traditional gender roles and values? If these roles and values are maintained in specific cultures, how and will they influence the overall economic well-being (and competitiveness) of those regions relative to other, more secular societies with different gender constructs? To understand these questions, further studies should be designed to include intertemporal change; how do perceived and actual opportunities and gender roles change over time in generally conservative societies? Clearly, more research is needed in this area-particularly of a comparative nature. 


\section{References}

Amin, Shahina, and Imam Alam. 2008. "Women's employment decisions in Malaysia: Does religion matter?" The Journal of Socio-Economics, 37(6), 2368-2379.

Bennardo, Giovanni. 2013. "Cognitive Anthropology." Oxford Bibliographies Online: Anthropology. doi: $10.1093 /$ obo/9780199766567-0070

Canham, Matt. 2014. "Mormon Populace Picks Up the Pace in Utah." The Salt Lake Tribune. Retrieved June 1, 2015, from http: " $\|$ w. sltrib.com news $18+2825-155$ mormon-populace-pichs-up-thepace'? fullpage=1.

CIA. (n.d.). "Religions." The World Factbook. Retrieved May 17, 2015 from htup: "ww.cid.gov librarvipublications the-11orld-factbonk tields/2122.html.

Dressler, William. 2004. "Cognitive Anthropology." In Encyclopedia of Social Science Research Methods, edited by Michael Lewis-Beck, Alan Bryman, and Tim Futing Liao, 140-141. Thousand Oaks, CA: SAGE Publications, Inc. doi: $\underline{10 .+135 / 9781+12950589 . n 133}$

Dubai Statistics Center. 2011. "Population (15 Years and Over) by Nationality, Sex and Economic Activity Status-Emirate of Dubai." Retrieved June 1, 2015 from

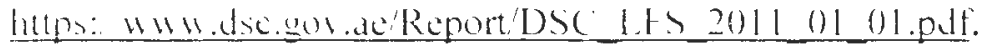

Feldmann, Horst. 2007. "Protestantism, labor force participation, and employment across countries." American Journal of Economics and Sociology, 66(4), 795-816.

The First Presidency and Council of the Twelve Apostles of the Church of Jesus Christ of Latter-day Saints. 1995. "The Family: A Proclamation to the World. The Church of Jesus Christ of Latterday Saints." Retrieved June 1 from https: Wwi./ds.org topics family-prockamation?'lans=eng.

Guiso, Luigi., Paola Sapienza, and Luigi Zingales, 2003. "People's opium? Religion and economic attitudes." Journal of Monetary Economics, 50(1), 225-282.

Hofstede, Geert. et al. 2010. Cultures and Organizations: Software of the Mind. New York, New York: McGraw Hill.

Hulsether, Mark. 2005. "Religion and Culture." In The Routledge Companion to the Study of Religion, edited by John Hinnells, 489-508. New York, New York: Routledge.

Iannccone, Laurence. 1998. "Introduction to the economics of religion." Journal of Economic Literature, 36, 1465-1496.

Kaufman, Gayle. 2005. "Gender Role Attitudes and College Students' Work and Family Expectations." Gender Issues, 22(2), 58-71. 
Keysar, Ariela, and Barry A. Kosmin. 1995. "The Impact of Religious Identification on Differences in Educational Attainment Among American Women in 1990." Journal For The Scientific Study Of Religion, 34(1), 49.

Landes, David. 1998. The Wealth and Poverty of Nations: Why Some Are So Rich and Some So Poor. New York, New York: W.W. Norton.

Meyer, Ann Elizabeth. 2013. Islam and Human Rights: Tradition and Politics. Boulder, Colorado: Westview Press.

Ministry of State for Federal National Council Affairs. 2008. "Women in the United Arab Emirates: A Portrait of Progress." Accessed 27 May 2015. http: "แแแ. uae-

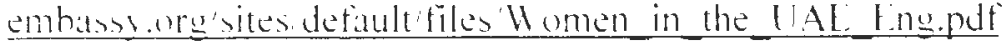

O'Neil, Mary Lou, and Mehmet Huseyin Bilgin. 2013. "Religion as a Factor Influencing Turkish Women's Decisions to Work." Journal of International Women's Studies, 14(3), 163-173.

al-Oraimi, Suaad Zayed. 2004. Gender and Development: The Role of Women in the Formal Economic Development and Political Spheres in the United Arab Emirates. Ann Arbor, MI: ProQuest Information and Learning Company.

Parks Langston, Lecia. 2010. “Choose Your Career, Don't Let it Choose You!” Utah Careers Supplement for Women. Utah Department of Workforce Services. Retrieved June 1, 2015, from hup: jub utah.gu wi pubs womencareers womennguide.html

Perlich, Pamela. 2006. "Long Term Demographic Trends Impacting Higher Education in Utah." Bureau of Economic and Business Research, University of Utah. Retrieved June 1, 2015, from htup: hebr.husiness.utah.edu sites hebr Documents sudies'H lighEd I rends.p.ti

Pinto, Vânia Carvalho. 2012. Nation-Building, State and the Genderframing of Women's Rights in the United Arab Emirates (1971-2009). Reading, United Kingdom: Ithaca Press.

Rosenlof, Celeste. 2014. "60\% of Utahns LDS in 2013, Gallup says." KSL.com. Retrieved June 1, 2015, from hup: "Iแ".hsl.com? sid=2879996?.

Stoelzel, Jean. 1983. Les valuers du temps présent. Paris: Presses Universitaires de France.

United Arab Emirates. 1971. Constitution of the United Arab Emirates. Accessed 27 May 2015. hup: "1"w.refiorld.orgdocid $48 \mathrm{eca} 8132 \mathrm{htm}$

U.S. Department of State. n.d.. "United Arab Emirates." Retrieved June 1, 2015, from htlp: "IIII.state.gov documents organization'171747.pdf

Utah Department of Workforce Services. 2014. "Hard at Work: Women in the Utah Labor Force." Retrieved June 1, 2015, from hups: jubs.utah.gov wipuhs womenciareers factsheel.hml 
Weber, Max. 1930. The Protestant Ethic and the Spirit of Capitalism (2001 ed.). New York, New York: Routledge.

The World Bank. 2015. "Labor force participation rate, female (\% of female population ages 15) (modeled ILO estimate)." Retrieved June 1, 2015, from

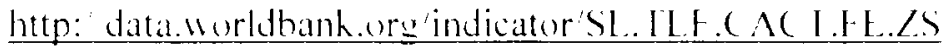




\section{Reflective Writing}

I first began work on this Honors thesis project two and a half years ago. When I began the project, I didn't anticipate all of the ups and downs that would be a part of the process. Although completing this project has easily been the most frustrating and complicated part of my undergraduate career, I have been grateful for the experience and the opportunities that I have had as a part of my work. From an international research opportunity to an international research presentation with a lot of hard work, delays, and red tape in between, I learned several lessons.

During the fall of 2012 (the beginning of my sophomore year), I learned that I could potentially qualify to represent USU as a participant at a women's leadership conference in Dubai, UAE, if I was willing to develop a research project that could justify sending me there. Because I was very interested in traveling and attending the conference, I began brainstorming with the help of the professor who would ultimately become my thesis mentor. After putting together a very short, simple research proposal, I was accepted to attend and notified about three months before the conference. This left me with limited time to apply for funding, begin my research, and plan my project. As such, I probably spent less time than I should have asking myself if this project was really the direction I wanted to go with my thesis. Looking back, I don't think I would have changed projects significantly. I would, however, have approached this project with entirely different expectations of myself and the process from the beginning.

I had determined to create and distribute a survey in Dubai and then distribute the same survey in Logan as a cross-cultural study. As I quickly discovered, however, writing and distributing a survey is not a simple as jotting down a couple of questions and passing them out to a couple of people. Because I hoped to do cross-cultural work, I had to take cultural differences into account to assure that my survey instrument would be valid in both locations. This process resulted in a series of conversations with 
professors in Dubai as I quickly learned about and sought the equivalent of IRB approval in the UAE. Because all steps of research inevitably take longer than anticipated, I was only able to finalize this process once I arrived in Dubai and it was impossible for me to fully distribute the survey while there. This, in turn, left me in the position of begging for survey responses from Emirati women electronically for the next six months until I had obtained a sufficient number of responses.

Meanwhile, I was working on the necessary literature review. Ideally, I would have completed the literature review before crafting the survey and beginning distribution, but this wasn't possible at the time considering the limitations I had with respect to my trip to Dubai. So, I simply had to learn from my process, plan to plan better on future projects, and move forward. With a cohort of complete, approved survey responses from Dubai and a literature review on the way, I began seeking IRB approval to distribute the survey in Logan on campus. This process again, proved frustrating as the approval process took nearly six months to complete-significantly longer than I had anticipated, delaying the opportunity for me to solicit responses on campus by an entire semester.

By this point, I felt like I had been inching along in the process forever. I began to lose interest in the project simply because I doubted my ability to sustain it as I continually encountered delays or circumstances that were largely out of my control. It was at this point in the project that working with my mentor was critical, because she believed in the project and felt that I could complete it. Her motivation and optimism helped me decide to see it through to the end, even as I faced significant and unexpected short-term health challenges. At her suggestion, we searched for interesting conferences to which we could submit proposals. Being accepted to present at a conference in Croatia helped keep me motivated through the difficult final year of work to complete the project.

Quite honestly, completing this project has felt stressful and frustrating more often than not. There were many days when it was easy to wonder why I was even bothering to care, and to assume that 
it wasn't worth it. Those days, however, were an important part of a process and a project that has ultimately shaped me into a different, more inquisitive, and more determined student. Completing this project has shown me that I can do things that are hard, things that I don't always want to do, and things that help me be better. I have had to be patient with myself, with others, and with the circumstances of life. I have balanced excitement, curiosity, delay, and disappointment. I have learned and grown and travelled and changed. And in the end, I think the real result of this project is not the survey data or the paper above. The result of this project is a significant shift in my perspectives and a deeper understanding of the research process. When I think about college in five, ten, or twenty years, this paper and data likely won't mean much to me in and of themselves. Rather, it is what they represent to me about myself and my time here that hold meaning. 


\section{About the Author}

Allison Fife was born in Logan, UT and lived in Arizona and Colorado before returning to Cache Valley, where she lived in Hyde Park and attended Sky View High School before coming to Utah State in 2011. As a student, Allison earned a dual-major in History and Economics and a minor in French. During her time at USU, Allison participated in the Huntsman Scholar Program, Koch Scholars, Bueller Scholars, Merrill Scholars, and the Honors and Undergraduate Research Fellows programs. In addition to membership in Phi Alpha Theta, Allison served as president of the Society for the Advancement of Ethical Leadership and as president of the Interfaith Student Association. Allison loves to travel and learn about other cultures; as a student, she visited ten different countries (France, UAE, Russia, Turkey, Italy, UK, Switzerland, Belgium, Germany, Croatia) through participation in three study abroad programs and two international conferences. She plans to study political science and international relations in graduate school, and hopes to make a difference for women, mothers, and children at home and abroad who face significant medical and educational life challenges. During her senior year, Allison fell in love and married a fellow student and friend, Joshua Hale. The Hales look forward to a happy life of learning and serving together. Allison enjoys spending time with family, serving others, and playing the piano. 